\title{
Modulation of intercellular communication by differential regulation and heteromeric mixing of co-expressed connexins
}

\section{E.C. Beyer ${ }^{1}$, J. Gemel ${ }^{1}$, K.H. Seul2, D.M. Larson ${ }^{3}$, \\ K. Banach ${ }^{4}$ and P.R. Brink ${ }^{4}$}

\author{
1Section of Pediatric Hematology/O ncology, \\ University of Chicago, Chicago, IL, USA \\ ${ }^{2}$ Chonbuk National Medical School, Chonbuk, Korea \\ ${ }^{3}$ Mallory Institute of Pathology, Boston, MA, USA \\ 4State University of New York, Stony Brook, NY, USA
}

\begin{abstract}
Correspondence
E.C. Beyer

Section of Pediatric

Hematology/O ncology

University of Chicago

MC 4060

5841 S. Maryland Ave.

Chicago, IL 60637-1470

USA

Fax: + 1-773-702-9881

E-mail:

ebeyer@ peds.bsd.uchicago.edu

Presented at the Meeting

"Gap Junctions in the Nervous and

Cardiovascular Systems: Clinical

Implications", Rio de Janeiro, RJ,

Brazil, June 6-11, 1998.

Research supported by NIH grants HL59199 and HL45466, a grant from the Bear Necessities Pediatric Cancer Research Foundation, and the Bernice M eltzer Pediatric Cancer

Research fund.
\end{abstract}

Received December 22, 1999

Accepted January 25, 2000

\section{Abstract}

Intercellular communication may be regulated by the differential expression of subunit gap junction proteins (connexins) which form channels with differing gating and permeability properties. Endothelial cells express three different connexins (connexin37, connexin40, and connexin43) in vivo. To study the differential regulation of expression and synthesis of connexin 37 and connexin43, we used cultured bovine aortic endothelial cells which contain these two connexins in vitro. RNA blots demonstrated discordant expression of these two connexins during growth to confluency. RNA blots and immunoblots showed that levels of these connexins were modulated by treatment of cultures with transforming growth factor- 31 . To examine the potential ability of these connexins to form heteromeric channels (containing different connexins within the same hemi-channel), we stably transfected connexin43-containing normal rat kidney (NRK) cells with connexin 37 or connexin40. In the transfected cells, both connexin proteins were abundantly produced and localized in identical distributions as detected by immunofluorescence. Double whole-cell patch-clamp studies showed that co-expressing cells exhibited unitary channel conductances and gating characteristics that could not be explained by hemi-channels formed of either connexin alone. These observations suggest that these connexins can readily mix with connexin43 to form heteromeric channels and that the intercellular communication between cells is determined not only by the properties of individual connexins, but also by the interactions of those connexins to form heteromeric channels with novel properties. Furthermore, modulation of levels of the co-expressed connexins during cell proliferation or by cytokines may alter the relative abundance of different heteromeric combinations.
Key words

- Endothelium

- Heteromeric connexons

- Intercellular communication

- Connexin37

- Connexin40 


\section{Introduction}

Gap junctions are formed by subunit proteins that are members of the multi-gene family of connexins $(\mathrm{Cx})$. We have previously used stable transfection of non-communicating cells with individual connexins to demonstrate that they each form intercellular channels with differing gating, conductance, and permeability/selectivity properties $(1,2)$. However, determining the characteristics of channels formed of individual connexins may not be sufficient to explain the properties of intercellular communication in most cells, since more than one connexin is expressed in the same cell in many, if not all, organs (including liver, heart, lens, bone, etc.).

Many of our studies have focused on cells of the vascular system which contain at least three connexins ( $\mathrm{Cx} 37, \mathrm{Cx} 40$, and $\mathrm{Cx} 43$ ). Individually, these proteins form channels with different physiological properties (1-3). However, these connexins have all been found within the same cell type (the endothelial cell), and in a number of cases they can be identified within the same individual cell (4-6). The relative abundance of these connexins varies in different endothelia.

This manuscript will present some new data and review some of our published data concerning the regulation and physiology of co-expressed connexins in primary cultures of endothelial cells and in transfected cell lines.

\section{Material and Methods}

Cell culture of bovine aortic endothelial cells has been described previously (7). Connexin mRNAs were detected by RNA blotting (4) and quantitated by scanning densitometry. Connexin proteins were detected by immunoblotting (7) or immunofluorescence $(8,9)$.

Cell lines were stably transfected with
Cx37 or Cx40 DNAs into the eukaryotic expression plasmids pSFFV-neo (4) or pcDNA3.1 (Invitrogen, Carlsbad, CA, USA) and stable colonies were selected using G418 (Life Technologies, Gaithersburg, MD, USA). Cell pairs were analyzed electrophysiologically by double whole-cell patch-clamp methods as described previously (10).

\section{Results}

\section{Differential regulation of endogenous Cx37 and Cx43 in endothelial cells}

One of the best in vitro models for the study of endothelial cells uses cultured bovine aortic endothelial cells (BAECs). Therefore, we studied the regulation of expression and synthesis of connexins in BAECs. RNA blots showed the presence of $\mathrm{Cx} 37$ and $\mathrm{Cx} 43$ in freshly isolated bovine aortic endothelium (4) and in BAECs soon after plating for cell culture $(4,7)$. Apparently, Cx40 was absent from aortic endothelium in this species or its expression was rapidly lost with adaptation of the cells to culture.

Since prior studies had shown variations in gap junction expression and intercellular communication in endothelial cells depending on cell growth and density $(11,12)$, we studied the levels of Cx43 mRNA and protein and Cx37 mRNA in cultures of BAECs under different conditions (7). During log phase growth of subconfluent cells in culture, $\mathrm{C} \times 43$ mRNA was maintained at high levels; then, as cultures reached confluency, Cx43 mRNA levels fell by 25\% (Figure 1). Levels of the $\mathrm{Cx} 43$ protein showed an even more dramatic decline at confluency (7). In contrast, Cx37 mRNA was only weakly detectable until the cultures became confluent, when $\mathrm{Cx} 37$ levels became similar to those of Cx43 (Figure 1).

We have used several interventions to elucidate mechanisms of connexin regulation. Our most extensive studies have investigated the effects of the growth inhibitory 
cytokine TGF- $\beta 1$ on endothelial connexins. Treatment of BAEC cultures with TGF- $\beta 1$ inhibited cell growth and caused an upregulation of $\mathrm{Cx} 43$ expression as measured by Cx43 mRNA content or $\mathrm{Cx} 43$ protein content and synthesis (7). Further experiments suggested that these changes were due to increased $\mathrm{Cx} 43$ transcription and translation as well as decreased protein degradation. In contrast, TGF- $\beta 1$ treatment had a different effect on $\mathrm{Cx} 37$; it abolished the increase of Cx37 mRNA seen in control cultures, maintaining Cx37 mRNA at constant low levels (7). Thus, treatment with this cytokine could modulate the relative levels of $\mathrm{Cx} 37$ and Cx43 (Figure 2).

\section{Heteromeric mixing of Cx37 or Cx40 with Cx43 in transfected cells}

Co-expression of multiple connexins in a single cell leads to the possibility of mixing of connexins within a single gap junction hemi-channel, forming "heteromeric" connexons. The formation of heteromeric hemichannels would allow the formation of a large number of channels beyond that possible by formation of only homomeric connexons containing a single connexin. Two co-expressed connexins could form 14 different hemi-channels, leading to the potential for making 196-gap junction channel types in a coupled pair of co-expressing cells (10). Heteromeric mixing of three co-expressed connexins would lead to correspondingly more possible channels.

The existence of heteromeric connexons is supported by biochemical studies using mammalian liver or lens $(13,14)$.

To examine the mixing of the connexins from endothelial cells and their ability to form heteromeric channels, we studied coexpressed connexin pairs in stably transfected cells. In some experiments, communication-deficient cells (Neuro2A or HeLa) were sequentially transfected with $\mathrm{Cx} 43$ and $\mathrm{Cx} 37$ (10) or $\mathrm{Cx} 43$ and $\mathrm{Cx} 40$ (Gemel $\mathrm{J}$ and
Beyer EC, unpublished data) using two different selectable markers. The co-transfected cells were analyzed using the double wholecell patch-clamp technique. Unlike cells expressing only a single connexin which exhibit a predominant unitary conductance, many single channel sizes were detected in

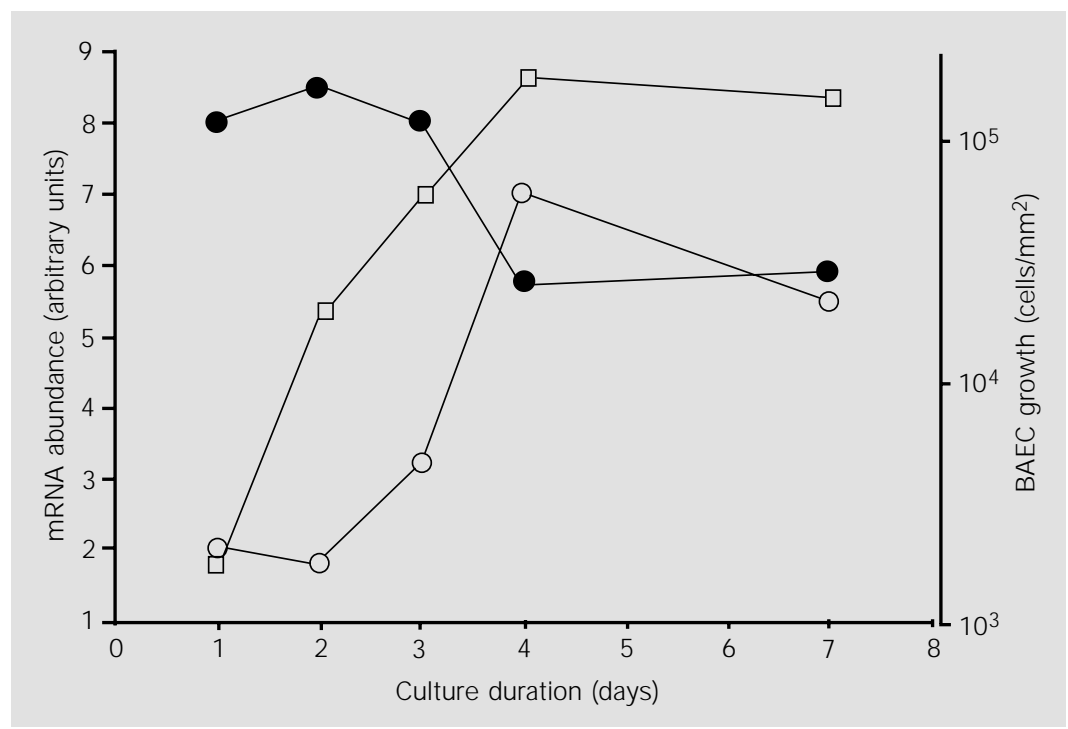

Figure 1 - Steady-state levels of connexin mRNAs during growth to confluency in bovine aortic endothelial cell (BAEC) cultures. Cx37 (open circles) and Cx43 (filled circles) mRNA levels were determined by densitometry of RNA blots (expressed in arbitrary units, mean \pm SD). BAEC growth (squares, expressed as cell density) was based on hemocytometer counting of parallel dishes. (Data are replotted based on Ref. 7).

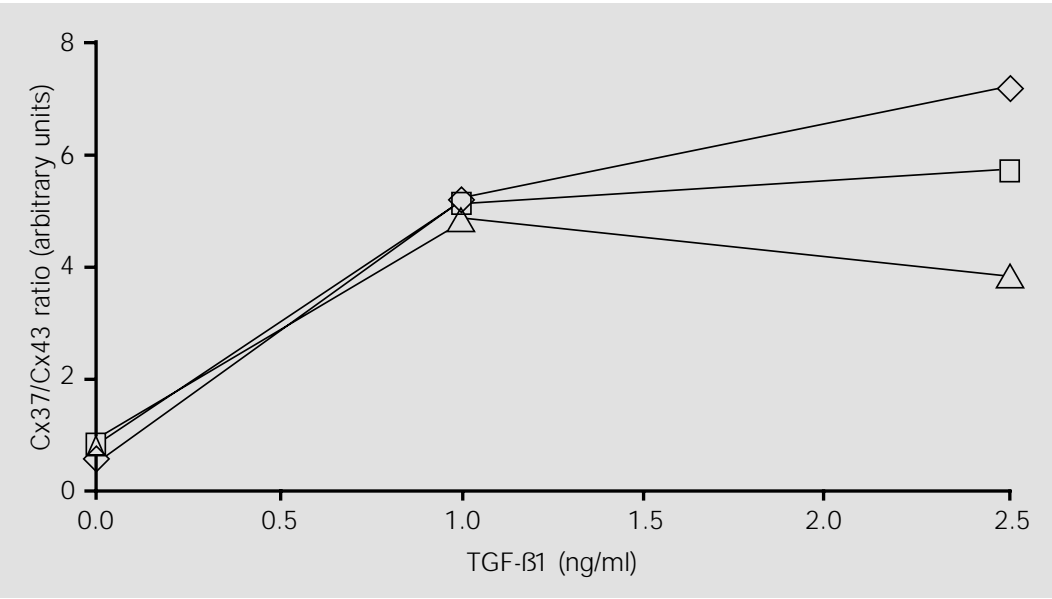

Figure 2 - Effects of long-term treatment with TGF-ß1 on connexin mRNA levels in BAECs. Cells were plated at low $\left(1 \times 10^{4} / \mathrm{cm}^{2}\right)$ (lozenges), medium $\left(2 \times 10^{4} / \mathrm{cm}^{2}\right)$ (squares), or high $(4$ $\times 10^{4} / \mathrm{cm}^{2}$ ) (triangles) density, treated with TGF-ß1 (at different doses as shown), and then processed for RNA blots. Densitometric results from those blots are expressed as the ratio of Cx43 to Cx37. (Data are replotted based on Ref. 7). 
the co-transfectants. In addition, in $\mathrm{Cx} 43$ / Cx37 cell pairs, the voltage-dependent decrease of the normalized conductance was shifted to higher voltages than observed with homotypic or heterotypic connexin combinations (10). Thus, both unitary conductance and voltage-dependent gating data suggested heteromeric mixing of connexins.

We have extended these studies using stable transfection of normal rat kidney (NRK) cells. NRK cells abundantly express $\mathrm{Cx} 43$, and are one of the most widely used systems for studies of the biochemistry and cell physiology of that connexin. To examine possible interactions of $\mathrm{Cx} 37$ or $\mathrm{Cx} 40$ with $\mathrm{Cx} 43$, we transfected NRK cells with human $\mathrm{Cx} 37$ cDNA (9) or rat $\mathrm{Cx} 40$ and selected stable clones using G418. RNA blot hybridization and immunoblotting demonstrated that the transfected cells abundantly expressed the transfected connexin as well as $\mathrm{Cx} 43$. The co-expressed connexins localized to identical distributions as demonstrated by immunofluorescence (Figure 3) and double-label experiments showed an exact correspondence of the connexin immunoreactivities (9).

We also performed electrophysiological analyses of the co-expressing NRK cells using the double whole-cell patch-clamp tech- nique. Data obtained from these cells were compared to data derived from parental NRK cell pairs. Weakly coupled cell pairs allowed the observation of single channel events. In experiments using a pipette solution containing $180 \mathrm{mM} \mathrm{CsCl}$, the conductance of $\mathrm{Cx} 43$ channels in the parental NRK cells was $115 \mathrm{pS}$. However, in the $\mathrm{Cx} 37 / \mathrm{Cx} 43$ or Cx40/Cx43 co-expressing cells no single channel size was predominant; rather, multiple unitary conductances were observed. For example, in the brief recording periods shown for NRK/Cx 40 cells (Figure 4) channel events of $11,32.5,57.7,82.5$ and $87.5 \mathrm{pS}$ were seen.

The voltage-dependent gating behavior also differed between single connexin-expressing cells and the co-expressing NRK transfectants. Homotypic pairs of cells expressing Cx37/Cx37 pairs (N2A/Cx37 (10)) or $\mathrm{Cx} 40 / \mathrm{Cx} 40$ (N2A/Cx40, Figure 5, middle panel) showed a strong voltage dependence, and pairs of cells expressing $\mathrm{Cx} 43 / \mathrm{Cx} 43$ (NRK, Figure 5, top panel) showed a weak voltage dependence. Heterotypic pairs showed a voltage-dependent asymmetry in transfected cells (10) or Xenopus oocytes. In contrast, the data from pairs of cells coexpressing $\mathrm{Cx} 43$ and $\mathrm{Cx} 37$ (10) or $\mathrm{Cx} 43$ and $\mathrm{Cx} 40$ (NRK/Cx40, Figure 5, bottom panel)
Figure 3 - Immunofluorescent localization of $\mathrm{Cx} 43(\mathrm{~A}, \mathrm{C})$ and $\mathrm{C} \times 40(\mathrm{~B}, \mathrm{D})$ in normal rat kidney (NRK) cells $(A, B)$ and in NRK cells transfected with human Cx40 (NRK/Cx40, panels C,D). Cells were simultaneously reacted with mouse anti-Cx43 and rabbit anti-Cx40 antibodies followed by FITC-conjugated goat anti-mouse and CY3-conjugated goat anti-rabbit secondary antibodies. Cx43 was detected at appositional membranes of both the parental and transfected NRK cells $(A, C)$. Anti-Cx40 antibodies showed only background reactivity with the parental NRK cells (B); but, in the NRK/CX40 cells, the introduced $\mathrm{C} \times 40$ was detected in an identical distribution to the endogenous $\mathrm{C} \times 43$ (compare $C$ and $D$ ), suggesting that gap junctions in these cells contain both connexins.

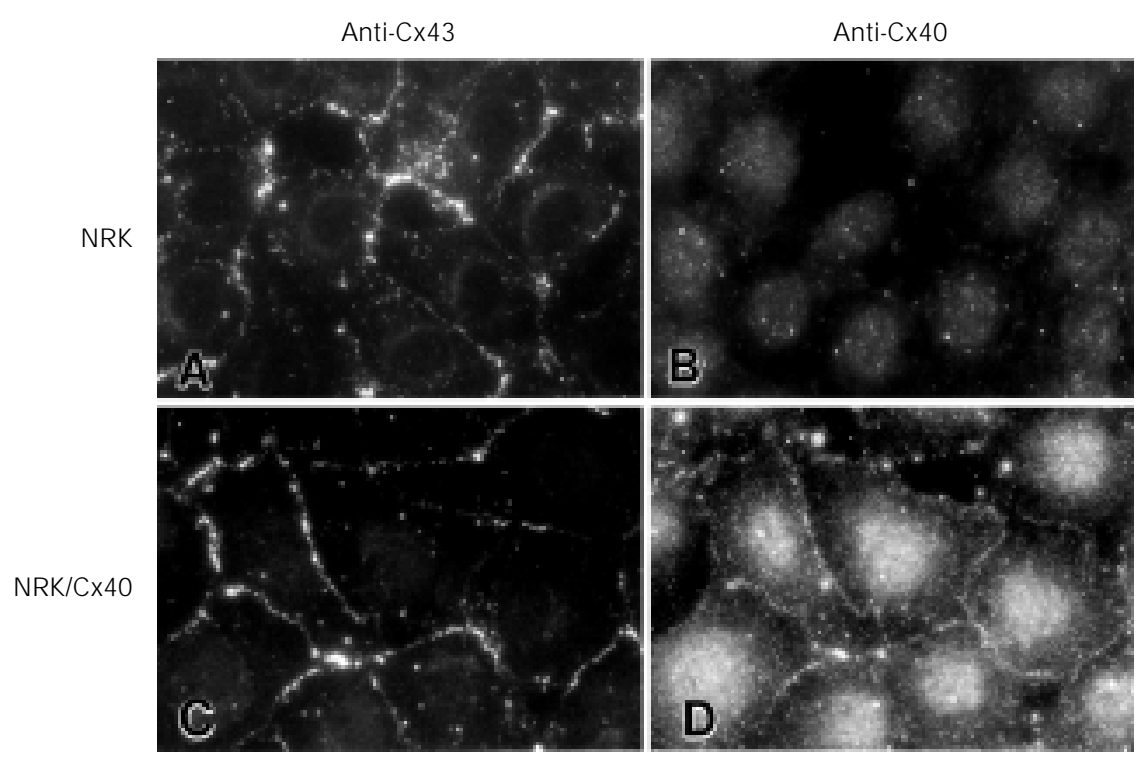


were much more scattered, and the voltagedependent decrease of the normalized conductance was shifted to higher voltages.

Taken together with our previously published results $(9,10)$, these data provide strong electrophysiologic evidence for heteromeric mixing of either $\mathrm{Cx} 37$ or $\mathrm{Cx} 40$ with $\mathrm{Cx} 43$.

\section{Discussion}

Endothelial cells contain multiple connexins both in vivo and in vitro. Our cultured BAEC experiments have demonstrated that the absolute levels of at least two of these connexins ( $\mathrm{Cx} 37$ and $\mathrm{Cx} 43)$ as well as the ratio of one to the other can be modulated by physiologically relevant conditions including growth to confluency and treatment with the cytokine TGF- $\beta 1$. Furthermore, we have shown strong evidence that in transfected cells the endothelial cell connexins ( $\mathrm{Cx} 37$, $\mathrm{Cx} 40$, and Cx43) can form heteromeric channels with differing properties from the channels formed by individual connexins. Similarly, He and colleagues (15) recently suggested that $\mathrm{Cx} 43$ and $\mathrm{Cx} 40$ could form heteromeric gap junction channels in vascular smooth muscle cells. It is apparent that many different heteromeric mixtures must form functional channels in the $\mathrm{Cx} 43 / \mathrm{Cx} 37$ or the Cx43/Cx40 co-expressing cells. The abundance of different heteromeric forms would be altered by changes in the ratios of the coexpressed connexins providing a mechanism for physiologic modulators to affect intercellular communication.

Our new data suggest the need for reevaluating the conclusions of some prior

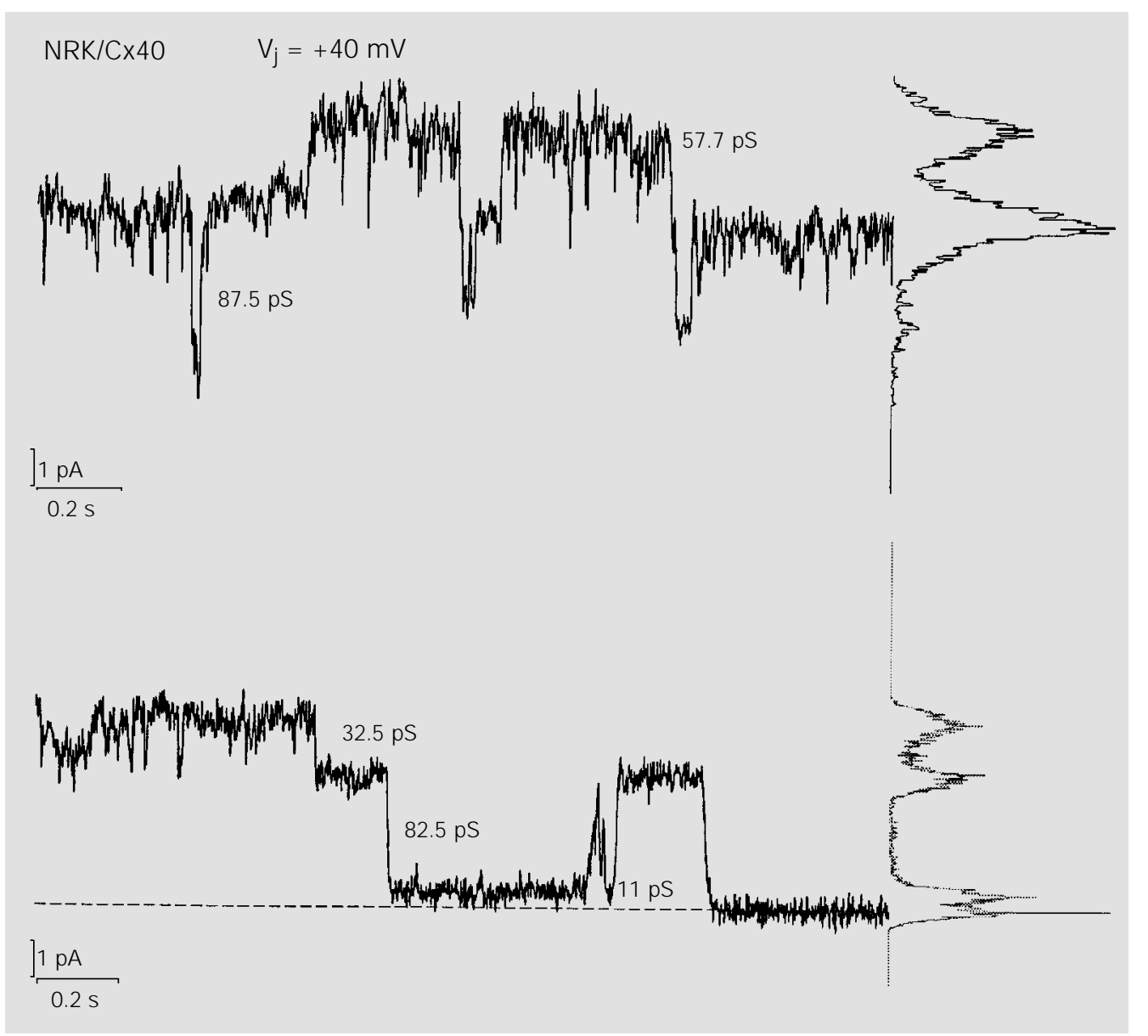

Figure 4 - Representative multichannel recordings of nomal rat kidney (NRK)/Cx40 cells. A transjunctional voltage step of +40 $\mathrm{mV}$ was applied. Recordings were performed using the double whole-cell patch-clamp technique with the pipette solution and the bathing solution containing $180 \mathrm{mM} \mathrm{CsCl}$ as the major solute (10). Different conductance levels are indicated next to channel events. Amplitude histograms for the data segments are shown on the right. 
Figure 5 - Conductance-voltage relationships for normal rat kidney (NRK) (top panel), N2A/Cx40 (middle panel), and NRK/CX40 (bottom panel) cell pairs. Representative data obtained from a short pulse protocol (400 ms) (10) are shown. Normalized conductance is plotted vs transjunctional voltage $\left(V_{j}\right)$ with different symbols representing different cell pairs.

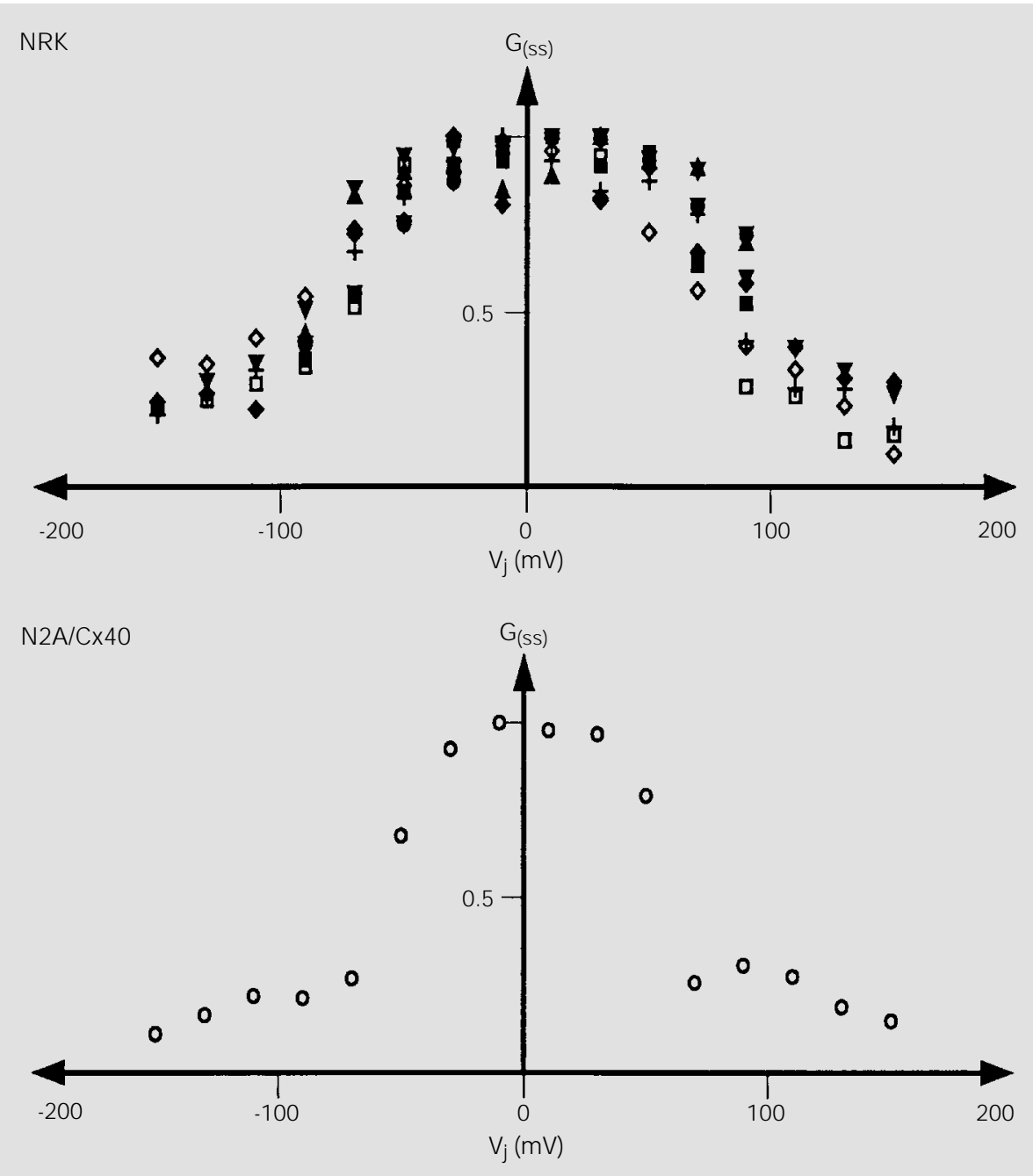

NRK/CX40

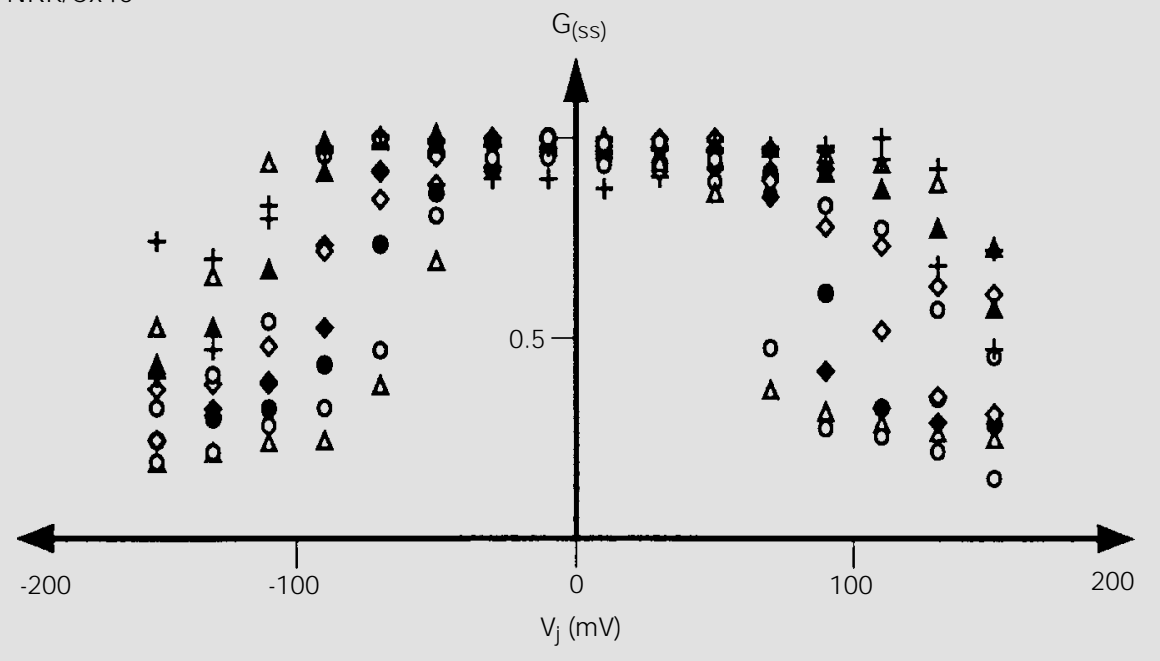


studies of connexin mixing. Several investigators have concluded that $\mathrm{Cx} 40$ and $\mathrm{Cx} 43$ are unable to form heterotypic gap junctional channels, since no significant intercellular conductance was detected when a $\mathrm{Xe}$ nopus oocyte expressing $\mathrm{Cx} 40$ was paired with an oocyte expressing Cx43 (16). The extrapolation that $\mathrm{Cx} 40$ and $\mathrm{Cx} 43$ are entirely incompatible is disputed by the data suggesting that $\mathrm{Cx} 40$ and $\mathrm{Cx} 43$ can form heteromers. The heteromeric condition is likely to have far more physiological significance than the heteromeric case, since there may be many cells (e.g., some endothelial cells or atrial myocytes) that co-express $\mathrm{Cx} 40$ and $\mathrm{Cx} 43$ while a potential heterotypic encounter could only occur at the as yet undiscovered site where a cell expressing only Cx40 meets one expressing only Cx43.

\section{References}

1. Veenstra RD, Wang HZ, Beyer EC, Ramanan SV \& Brink PR (1994). Connexin 37 forms high conductance gap junction channels with conductance state activity and selective dye and ionic permeabilities. Biophysical J oumal, 66: 1915-1928.

2. Veenstra RD, Wang $\mathrm{HZ}$, Beblo DA, Chilton MG, Harris AL, Beyer EC \& Brink PR (1995). Selectivity of connexin-specific gap junctions does not correlate with channel conductance. Circulation Research, 77: 1156-1165.

3. Beblo DA, Wang HZ, Beyer EC, Westphale EM \& Veenstra RD (1995). Unique conductance, gating, and selective permeability properties of gap junction channels formed by connexin40. Circulation Research, 77: 812-822.

4. Reed KE, Westphale EM, Larson DM, Wang $\mathrm{HZ}$, Veenstra RD \& Beyer EC (1993). Molecular cloning and functional expression of human connexin37, an endothelial cell gap junction protein. J ournal of Clinical Investigation, 91: 997-1004.

5. Gabriels J E \& Paul DL (1998). Connexin43 is highly localized to sites of disturbed flow in rat aortic endothelium but connexin37 and connexin40 are more uniformly distributed. Circulation Research, 83: 636-643.
6. Yeh HL, Rothery S, Dupont E, Coppen SR \& Severs NJ (1998). Individual gap junction plaques contain multiple connexins in arterial endothelium. Circulation Research, 83: 1248-1263.

7. Larson DM, Wrobleski MJ, Sagar GDV, Westphale EM \& Beyer EC (1997). Differential regulation of connexin43 and connexin37 in endothelial cells by cell density, growth, and TGF-betal. American J oumal of Physiology, 272: C405-C415.

8. Steinberg $\mathrm{TH}$, Civitelli R, Geist ST, Robertson AJ , Hick E, Veenstra RD, Wang HZ, Warlow PM, Westphale EM, Laing J G \& Beyer EC (1994). Connexin43 and connexin45 form gap junctions with different molecular permeabilities in osteoblastic cells. EMBO J oumal, 13: 744-750.

9. Beyer EC, Seul KH, Larson DM, Banach K \& Brink PR (1997). Heteromeric connexon formation: analyses using transfected cells. In: Werner R (Editor), GapJ unctions. ISO Press, Amsterdam, 91-95.

10. Brink PR, Cronin K, Banach K, Peterson E, Westphale EM, Seul KH, Ramanan SV \& Beyer EC (1997). Evidence for heteromeric gap junction channels formed from rat connexin43 and human connexin37. American J ournal of Physiology, 273: C1386-C1396.
11. Larson DM (1988). Intercellular junctions and junctional transfer in the blood vessel wall. In: Ryan US (Editor), Endothelial Cells. Vol. 3. CRC Press, Boca Raton, FL, 75-88.

12. Pepper MS, Spray DC, Chanson $M$, Montesano R, Orci L \& Meda P (1989). J unctional communication is induced in migrating capillary endothelial cells. J ournal of Cell Biology, 109: 3027-3038.

13. Bevans CG, Kordel M, Rhee SK \& Harris AL (1998). Isoform composition of connexin channels determines selectivity among second messengers and uncharged molecules. J ournal of Biological Chemistry, 273: 2808-2816.

14. J iang J X \& Goodenough DA (1996). Heteromeric connexons in lens gap junction channels. Proceedings of the National Academy of Sciences, USA, 93: 1287-1291.

15. He DS, J iang J X, Taffet SM \& Burt J M (1999). Formation of heteromeric gap junction channels by connexin 40 and 43 in vascular smooth muscle cells. Proceedings of the National Academy of Sciences, USA, 96: 6495-6500.

16. White TW, Paul DL, Goodenough DA \& Bruzzone R (1995). Functional analysis of selective interactions among rodent connexins. Molecular Biology of the Cell, 6 : 459-470. 